\title{
Day Time Activity Budgets, Height Utilization and Husbandry of Two Zoo-Housed Goodfellow's Tree Kangaroos (Dendrolagus goodfellowi buergersi)
}

\author{
Katherine Finch * and Amy Humphreys
}

check for

updates

Citation: Finch, K.; Humphreys, A. Day Time Activity Budgets, Height Utilization and Husbandry of Two Zoo-Housed Goodfellow's Tree Kangaroos (Dendrolagus goodfellowi buergersi). J. Zool. Bot. Gard. 2022, 3, 102-112. https://doi.org/10.3390/ jzbg3010009

Academic Editors: Kris Descovich, Caralyn Kemp and Jessica Rendle

Received: 26 October 2021

Accepted: 18 February 2022

Published: 4 March 2022

Publisher's Note: MDPI stays neutral with regard to jurisdictional claims in published maps and institutional affiliations.

Copyright: (C) 2022 by the authors. Licensee MDPI, Basel, Switzerland. This article is an open access article distributed under the terms and conditions of the Creative Commons Attribution (CC BY) license (https:// creativecommons.org/licenses/by/ $4.0 /)$.

\author{
Chester Zoo, North of England Zoological Society, Upton-by-Chester, Chester CH2 1LH, UK: \\ a.humphreys@chesterzoo.org \\ * Correspondence: k.finch@chesterzoo.org
}

\begin{abstract}
Goodfellow's tree kangaroos (Dendrolagus goodfellowi) are an endangered, arboreal macropod native to the lower, mid-montane rainforests of Papua New Guinea. Despite a number of holders keeping D. goodfellowi in zoos across the world, there is a lack of recent published work on this species. Here, we present daytime activity budgets, document height use and provide husbandry information for two Goodfellow's tree kangaroos (Dendrolagus goodfellowi buergersi) housed at Chester Zoo, UK. Throughout the observation period, both individuals spent the majority of their time resting within the environment but also spent time engaging in vigilance, travel and feeding behaviour. Additionally, despite the age and sex differences of the study individuals, both animals used the highest height level in the indoor habitat most frequently. We aim to share our information and encourage knowledge transfer with other holders, to both increase understanding and promote evidence-based management of this species.
\end{abstract}

Keywords: tree kangaroo; zoos; behaviour; activity budget; enclosure use; Dendrolagus; understudied

\section{Introduction}

Tree kangaroos (Genus: Dendrolagus) are a unique and fascinating member of the Macropodidae family, which inhabit rainforests across Irian Jaya, Papua New Guinea and Northern Queensland, Australia [1]. As the name suggests, most species of tree kangaroo live an arboreal lifestyle, using trees to rest, forage and travel between different areas [2]. Physiological adaptations such as long claws, rubber-like foot soles, a long tail and specialized limb morphology allow some species, including D. goodfellowi and D. matschiei, to be specialists in the forest canopy $[3,4]$.

Behavioural research has revealed that many species of tree kangaroo have low activity levels, with studies observing individual engagement in long periods of rest followed by bouts of locomotion [5]. When not resting, tree kangaroos spend time feeding, foraging [6] and performing vigilance behaviour [7]. Patterns of activity are noted to differ across wild Dendrolagus species, ranging from crepuscular [8] to nocturnal [9]. However, quantifying activity patterns and time budgets of tree kangaroos has proved challenging, due to the difficulty in tracking wild individuals through the dense forest canopy [10]. As such, the development and evaluation of new non-invasive techniques to monitor tree kangaroos has become increasingly popular [5]. Some low disturbance methods that are currently being trailed include faecal and scratch mark monitoring, utilizing remote cameras and implementing facial recognition software [10].

Identifying new techniques to monitor and observe tree kangaroos has never been more important as wild populations have plummeted in recent decades, leading to 12 of the 14 species of tree kangaroo being listed as threatened by the IUCN [11,12]. Factors which are attributed to this decline include habitat fragmentation $[13,14]$, conflict with human communities and climate change [12]. Dabek and Valentine [12] highlight that the survival 
of tree kangaroos is most strongly linked to the human communities in their native habitat. However, research suggests that contributions from government, NGO's and zoos are all significant and should not be overlooked [12].

Tree kangaroos have been held in zoos for over a century [15] due to their conservation status and their unique appearance. Extensive population management strategies have been implemented in the form of international studbooks to ensure ex-situ populations of tree kangaroos are as genetically diverse and demographically stable as possible [16]. In addition to this, husbandry practices have been evaluated and vastly improved, with the aim of enhancing the welfare state of zoo-housed individuals [17]. D. goodfellowi has received an increasing level of attention from the World Association of Zoos and Aquaria (WAZA), who endorsed a Global Species Management Plan (GSMP) in 2013 for this species. With an ex-situ population of just 55 individuals, low genetic diversity and low number of holders, international cooperation has been suggested to be vital for the maintenance of a healthy, sustainable population of D. goodfellowi in zoos [18]. In addition to facilitating ex-situ breeding opportunities for threatened tree kangaroo species, zoos provide an opportunity to study this elusive family of macropods in more detail than would be possible in the wild. As such, they are well placed to contribute to the knowledge base for this understudied species.

Data collection on individual-level behaviour is suggested to be of great importance to the success of keeping tree kangaroos ex-situ [17]. An individual evidence-based management approach has been paramount in providing optimum care [17], allowing keepers to adapt husbandry techniques and resource provision based on the needs of each animal. Throughout the study, we aim to provide husbandry information, outline day-time activity budgets and document height use of two Goodfellow's tree kangaroos housed at Chester Zoo, UK. The aim of this study is two-fold; to provide some information on this understudied species and to use the publication of these data to encourage knowledge transfer between holders of tree kangaroos.

\section{Materials and Methods}

\subsection{Study Subjects}

Study subjects were two Goodfellow's tree kangaroo $(1 \mathrm{M}, 1 \mathrm{~F})$ (Dendorolagus goodfellowi buergersi) housed at Chester Zoo, UK. Goodfellow's tree kangaroo are an endangered species of tree kangaroo native to the mid-montane forests of Papua New Guinea [19]. D. goodfellowi are easily distinguishable from other species of tree kangaroo, due to their warm red coloured pelage, golden yellow limbs and long golden and brown non-prehensile tail [20]. Sexual dimorphism is limited in this species, with male specimens only slightly larger than females [3]. D. goodfellowi has a life expectancy of approximately 8 years in the wild [21] and over 14 years in captivity [15].

At the time of data collection for this study, the male subject was 2 years of age (date of birth (DOB): 15 May 2017) and the female subject was approximately 18 years of age (DOB: 16 December 2001) [22]. Due to the age of the female study subject and the species' solitary nature within the wild [19] individuals were housed separately for the duration of the study with alternating access between off-show and on-show facilities. Data were collected when individuals were housed in the 'on-show' facility, so the animals had equal opportunity to utilize the same space, with the same habitat resources but at different data collection periods. Individuals were fed on a species-appropriate diet throughout the data collection period (Appendix A, Figure A1).

\subsection{Enclosure Information}

Behavioural data collection took place whilst individuals were housed in a custom tree kangaroo exhibit in the 'Islands' expansion of Chester Zoo that opened in 2018. Indoor enclosure dimensions were $3.65 \mathrm{~m}$ (Width) $\times 0.93 \mathrm{~m}$ (Depth) $\times 4.43 \mathrm{~m}$ (Height), giving a total indoor volume of $15.04 \mathrm{~m}^{3}$. The open air outdoor enclosure dimensions were $247 \mathrm{~m}^{2}$, with planting and branching available for individuals to climb to a maximum height of 
approximately $4 \mathrm{~m}$. All enclosure dimensions were obtained from architectural drawings and not measured by the authors.

The outdoor facility was a mixed-species area, with the study subjects sharing the outdoor environment with dusky pademelons (Thylogale brunii). Thylogale brunii are a species of forest-dwelling terrestrial macropod endemic to Papua New Guinea, currently listed as 'Vulnerable' to extinction by the IUCN [23]. No interactions between the species were recorded throughout the observation period. To travel between the indoor and outdoor facilities, individuals were provided with branching, allowing access to the indoor facility at a height of $2.6 \mathrm{~m}$. The branching provided differed in texture and width for grip and to encourage a wider range of movement and utilisation of the facility. To quantify height use, both the indoor and outdoor habitats were divided into height 'levels'. Recognisable features were used to distinguish between height levels to ensure accuracy of data collection. Additionally, height levels were divided to include relevant habitat resources (Table 1). Once height levels had been established, each level was measured (by KF) to provide additional information for the reader. The substrate of the indoor environment was coir and the substrate of the outdoor environment was bark chippings. Internal enclosure temperature was kept between $18-22{ }^{\circ} \mathrm{C}$ throughout data collection as recommended in the species husbandry guidelines [17]. Food was mainly presented in an elevated bowl (height approximately $1.3 \mathrm{~m}$ from the ground), with browse presented at varying heights within the facility to encourage locomotor behaviours.

Table 1. Indoor and outdoor facility height levels were used to quantify height utilisation. Outlined are the name of the height level, height in meters of each level and relevant habitat resources within each area.

\begin{tabular}{cccc}
\hline Facility & Height Level & Height $(\mathbf{m})$ & Habitat Resources \\
\hline \multirow{3}{*}{ Indoor } & Ground level & 0 & Coir substrate. \\
\cline { 2 - 4 } & Level One & $0.01-1.22$ & Fixed wooden structure, fixed and flexible branching. \\
\cline { 2 - 4 } & Level Two & $1.23-2.56$ & Food bowl, tree stump, fixed and flexible branching. \\
\cline { 2 - 4 } Outdoor & Level Three & $2.57-4.43$ & Access to outdoor facility, fixed and flexible branching. \\
\cline { 2 - 4 } & Ground level & 0 & Bark chipping substrate. \\
\cline { 2 - 4 } & Level One & $0.01-1.32$ & Flexible branching and ferns. \\
\cline { 2 - 4 } & Level Three & $2.33-4.00$ (approx) & $\begin{array}{c}\text { Access to indoor facility, fixed and flexible branching. } \\
\text { Includes higher branches of live trees. }\end{array}$
\end{tabular}

\subsection{Husbandry Routine}

Throughout data collection, both individuals were managed within the same husbandry routine. Daily keeper routine included the following; provision of fresh food as per species-specific individual diet sheet, cleaning away old food items, removing any soiled substrate, scrubbing and re-filling water drinkers, watering plants, visual health checks of individuals and checking security fencing around the exhibit. If required, the following tasks would also be completed; cleaning of indoor and outdoor windows, replacement of existing furnishings with new ones, e.g., logs and branching, raking substrate and removing old debris such as branches, twigs and stones, trimming back foliage within exhibit, cleaning signage, top-up of substrate within exhibit and public area maintenance.

Procedures and checks are also conducted as part of routine health monitoring. These include but are not limited to; regular weight measurements, nail inspection for nail trims, and the collection of faecal samples for the evaluation of female cyclicity and endo-parasite load. On-site veterinary, endocrinology and specialist animal care staff work holistically to ensure monitoring is timely and with animal well-being as the highest priority. 


\subsection{Behavioural Data Collection}

Behavioural data were collected via live continuous focal sampling, for $60 \mathrm{~min}$ observation sessions [24] between the hours of 09:00-17:00 using a pre-determined ethogram (Table 2, Supplementary Materials) at public viewing areas. Data collection schedule was designed to ensure each hour period was observed throughout the study period for each individual. Height utilization data were collected simultaneously using pre-defined enclosure height levels (Table 1, Appendix A, Figures A2 and A3). Behaviour data were recorded using a Microsoft Surface Go (Model 1.824) tablets programmed with an Excel time stamp formula (programmed by KF). Behavioural observations were conducted by trained members of the Behaviour and Welfare team at Chester Zoo. Although inter-observer reliability for this study was not calculated, inter-observer reliability scores [24] were calculated for previous projects with the same observers, with a matched sample score of $85 \%$. The sampling period for each individual was as follows Male: 20/02/2020-12/03/2020 (20/02: 2.8 h, 21/02: 3.3 h, 2/03: 1 h, 3/03: 1 h, 5/03: 2 h, 9/03: 1 h, 10/03: 1 h, 12/03: 1 h). Female: 11/11/2019-15/11/2019 (11/11: 1 h, 12/11: 3 h, 13/11: 2.2 h, 14/11: 1 h, 15/11: 2.1 h). Total observation time was $13.1 \mathrm{~h}$ for the male subject and $9.3 \mathrm{~h}$ for the female subject. Average dawn and dusk times for the sampling periods were as follows; Male: Dawn 07:04, Dusk 17:31, Female: Dawn 07:31, Dusk 16:18 [25].

Table 2. Ethogram of behaviours, allocated behavioural category used for data visualisation, full description of behaviour and reference for reader to access supplementary files of behaviour. Ethogram adapted from Dabek [26].

\begin{tabular}{|c|c|c|c|}
\hline $\begin{array}{l}\text { Behaviour } \\
\text { Category }\end{array}$ & Behaviour & Description & $\begin{array}{l}\text { Supplementary } \\
\text { Video File Reference }\end{array}$ \\
\hline Vigilance & Vigilance & $\begin{array}{l}\text { Sp. is actively observing and aware of } \\
\text { surroundings. Eyes are open and individual is alert. } \\
\text { If face not visible then head is visibly moving. }\end{array}$ & S1.1 and S1.2 \\
\hline Feeding & Feeding & $\begin{array}{l}\text { Sp. is actively chewing or consuming food items or } \\
\text { browse. Includes sp. reaching over to retrieve or } \\
\text { manipulate browse or food item. Includes } \\
\text { drinking behaviour. }\end{array}$ & \\
\hline Grooming & Grooming & $\begin{array}{l}\text { Sp. is scratching with fore limb or hind limb at a } \\
\text { specific area of the body. Includes sp. rubbing } \\
\text { oneself against items within the enclosure. }\end{array}$ & \\
\hline Travel & Travel & $\begin{array}{l}\text { Sp. is moving from one area of the enclosure to } \\
\text { another, in a forward or backward direction. } \\
\text { Includes horizontal and vertical climbing, leaping } \\
\text { to the ground, descending branches or objects, } \\
\text { quadrupedal walking or bipedal hopping. }\end{array}$ & $\mathrm{S} 1.3$ and $\mathrm{S} 1.4$ \\
\hline Rest & Rest-awake & $\begin{array}{l}\text { Sp. is relaxed with eyes open. Body posture is } \\
\text { slightly curled, with tail hanging down in a } \\
\text { relaxed manner. }\end{array}$ & S1.5 \\
\hline Rest & Rest—asleep & $\begin{array}{l}\text { Sp. is relaxed with eyes shut. Body curled with } \\
\text { face pointing downwards and forelimbs tucked in. }\end{array}$ & S1.6 \\
\hline Other & Excretion & Sp. is urinating or defecating. & \\
\hline Other & Yawning & $\begin{array}{l}\text { Sp. is opening mouth widely with a deep } \\
\text { inhalation of breath seen in diaphragm. }\end{array}$ & \\
\hline Other & Sniffing & $\begin{array}{c}\text { Sp. nose is extended towards an area or object. } \\
\text { Inhalation of air can be seen through flaring } \\
\text { of nostrils. }\end{array}$ & S1.7 \\
\hline
\end{tabular}

The observational data collected here formed part of routine, internal behaviour monitoring, which was commissioned by the collections staff at Chester Zoo and facilitated by Chester Zoo's in-house behaviour and welfare science team to allow for an evidencebased approach to management of individuals of different age and sex classes. 


\subsection{Statistical Analysis}

Due to the small sample size of this study, descriptive statistics were conducted in $\mathrm{R}$ (v1.3.2) [27] and presented throughout, with superficial comparisons made between study subjects using raw data. In line with other zoo-based studies, each day of observation was treated as an experimental unit; when more than one observation period occurred each day, an average of these observation sessions were taken [28]. Shapiro-Wilks tests for normality revealed the data to be non-normally distributed, as such the results are presented in the text using median (Mdn) and interquartile ranges (IQR). For results in graphical form, results are presented using $\mathrm{Mdn}$, first quartile (Q1), third quartile (Q3) and range values of the data. For additional information, mean values were also presented graphically. ggplot2 $R$ package [27] was used to construct jitter plot graphs.

\section{Results}

\subsection{Activity Budget}

Both study subjects spent the majority of the observation period resting (Male; Mdn: 52.57, IQR: 22.06, Female; Mdn: 79.64, IQR: 16.790, Figure 1), followed by vigilance behaviour (Male; Mdn: 28.70, IQR: 20.76, Female; Mdn 11.06, IQR: 2.29, Figure 1). 'Other' behaviours includes excretion, yawning and sniffing (Table 2). The male spent $5.33 \%$ more time feeding and $1.98 \%$ more time travelling than the female during the observation period for each individual.
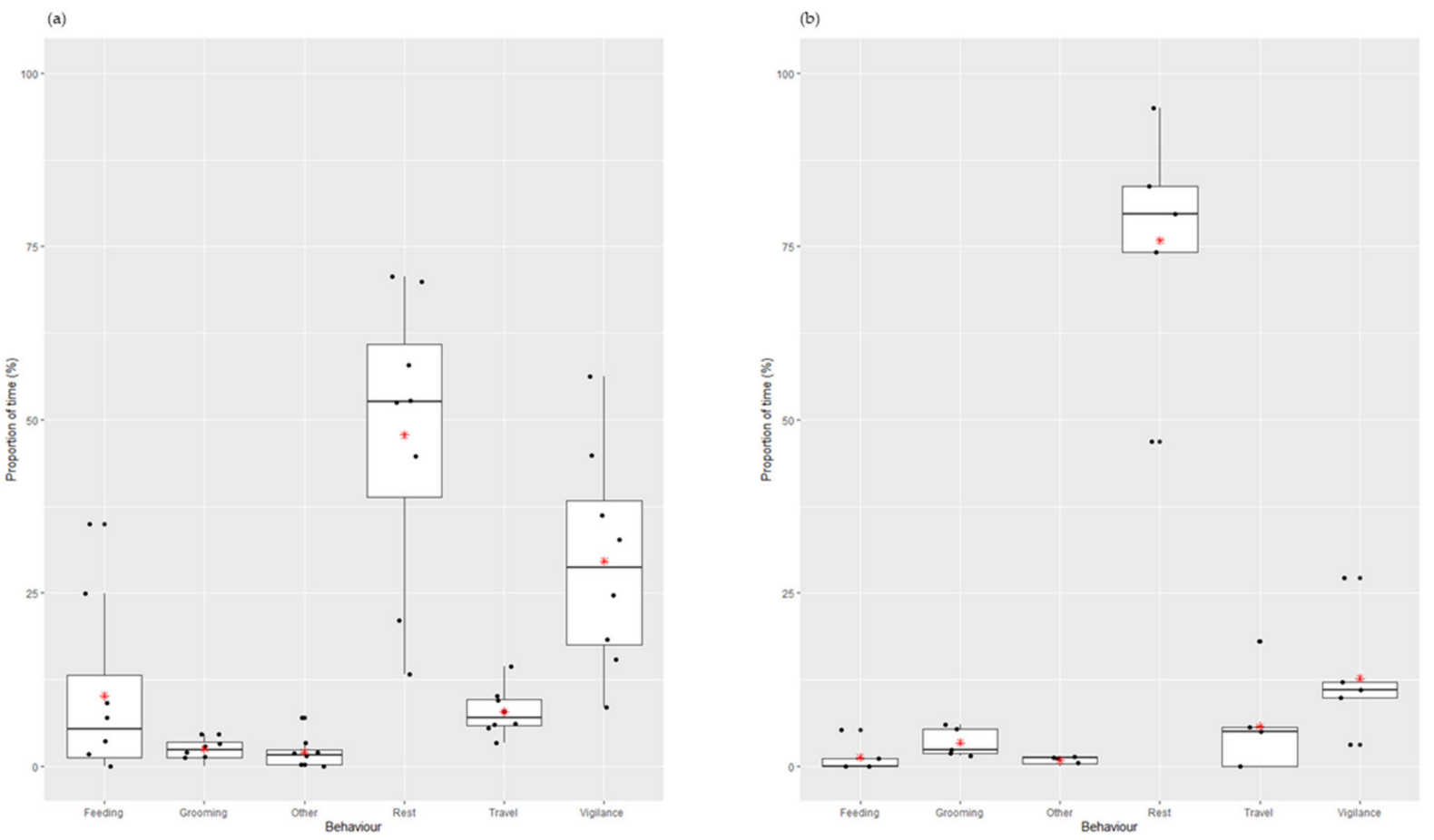

Figure 1. Proportion of time (\%) the (a) male study subject and (b) female study subject engaged in each behavioural category throughout the data collection period. Time budget displayed using boxplots outlining the first quartile, median, third quartile and range of the data. Jitter plots used to visualize each collected data point represented by black circles. Red star denotes the mean value of time spent engaging in each behavioural category.

\subsection{Height Utilisation}

As the size of the height levels were not consistent between the indoor and outdoor environment, results for individual height utilization during the study period were investigated separately. Average proportion of time spent in the outdoor habitat was low for each individual, with the male and female study subject spending $9.64 \%$ and $0.85 \%$ of total observation time outdoors, respectively. In consequence, height use data from the outdoor environment were not presented in a graphical format. 
When using the indoor habitat, the male subject spent most of his time at height level 3 (Mdn: 63.04, IQR: \pm 10.98, Figure 2), followed by height level 2 (Mdn: 34.84, IQR: \pm 17.15), ground level (Mdn: 3.91, IQR: \pm 4.72 ) and the least amount of time at height level 1 (Mdn: 3.51, IQR: \pm 7.99). When using the indoor habitat, the female study subject also utilised height level 3 most frequently (Mdn: 41.05, IQR: \pm 50.19, Figure 2), followed by height level 1 (Mdn: 15.50, IQR: \pm 27.24) then height level 2 (Mdn: 12.79, IQR: \pm 55.18). The female study subject spent no time at ground level throughout the study period (Mdn: 0, IQR: \pm 0 ).
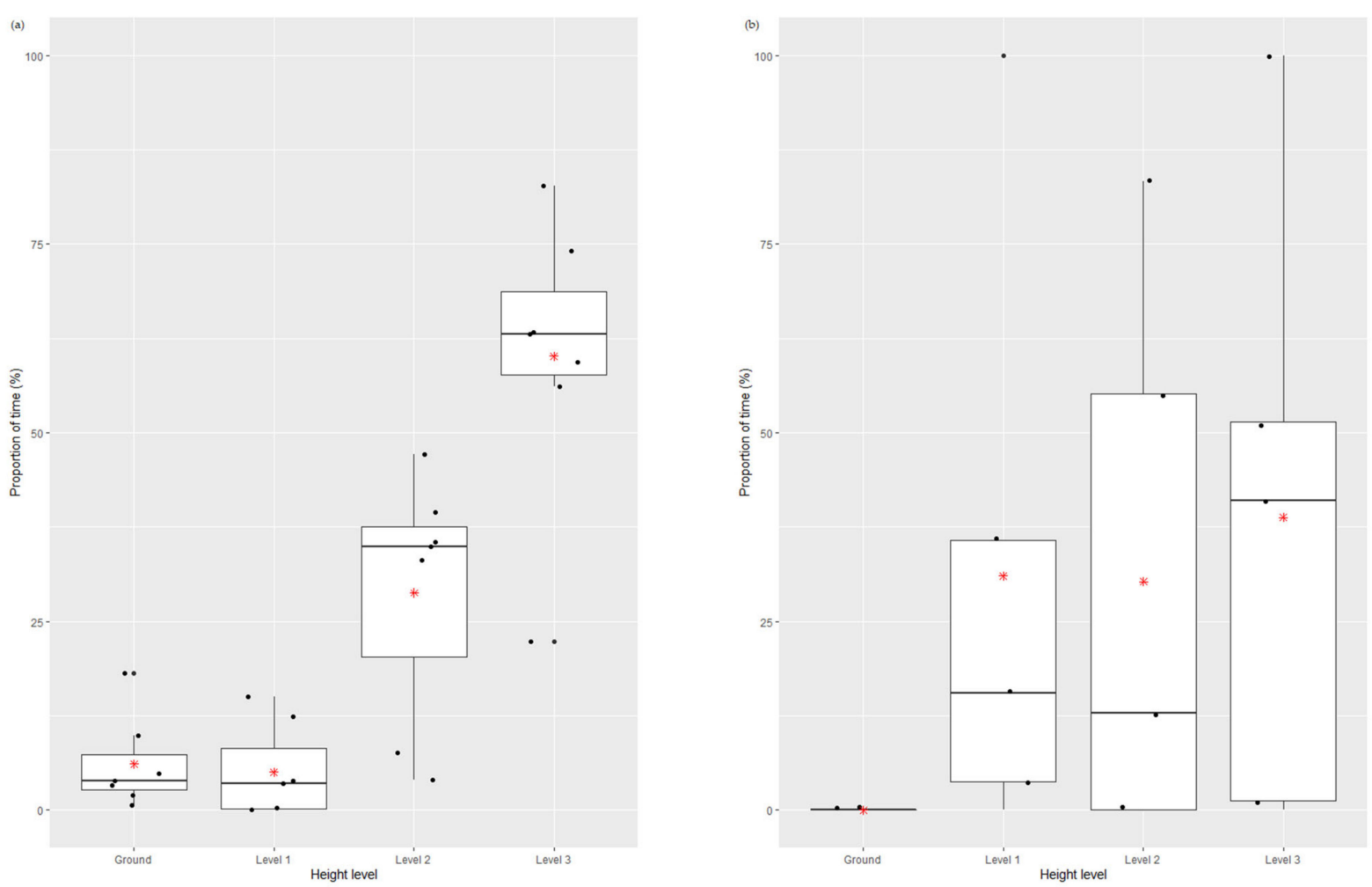

Figure 2. Proportion of time (\%) the (a) male study subject and (b) female study subject spent at different height levels whilst in the indoor habitat. Height use data displayed using boxplots outlining the first quartile, median, third quartile and range of the data. Jitter plots used to visualize each collected data point represented by black circles. Red star denotes the mean value of time spent utilizing each height.

\section{Discussion}

\subsection{Activity Budget}

Tree kangaroos are notoriously elusive [29]. Therefore, the observation of these individuals in a zoo environment provides a unique opportunity to add to the knowledge base of this understudied species. Research has highlighted the low activity levels of this species, reporting long periods of resting behaviour interspersed with locomotion and feeding behaviour [5]. A similar trend was found within this study with both individuals spending the majority of their time resting (Figure $1 \mathrm{a}, \mathrm{b}$ ). Additionally, both individuals spent a proportion of time engaging in 'vigilance' behaviour. Although Goodfellow's tree kangaroos do not encounter many predators of a similar body size in their native Papua New Guinea, both arboreal and terrestrial predators, including humans, still pose a risk [7]. Studies on Lumholtz's tree kanagroos (D. lumholtzi) highlighted an increase in vigilance behaviour when exposed to odour cues from predatory species [7]. This suggests that as a species vulnerable to predation, vigilance behaviour can form an important part of a tree kangaroos' activity budget. Furthermore, as this data collection took place whilst the zoo was open to the public, there could be the potential for human disturbance to be causing the study animals to display increased vigilance behaviour. Zoo visitors have been known to cause behavioural change in zoo-housed individuals [30], however the visitor effect has 
yet to be evaluated on this species. Further data collection, over a $24 \mathrm{~h}$ period or when individuals are housed off-show, may be useful to consider whether visitor presence may be affecting the activity budget of the study subjects.

When investigating time spent travelling, the female study subject spent $1.98 \%$ less time engaging in travel behaviour than the younger male subject. Most species of tree kangaroo are exceptionally well adapted climbers, allowing for individuals to navigate with ease through their native habitat of rainforest canopy [19]. However, to ensure optimum welfare experience, captive facilities may necessarily modify habitat resources to facilitate individual requirements [17]. Additionally, it is important to note that the behaviour data collection only occurred between the hours of 09:00-17:00, thus is not representative of a full $24 \mathrm{~h}$ activity budget for these individuals. Tree kangaroo activity budgets have been found to differ amongst species, ranging from crepuscular to nocturnal [8,9]. Thus, natural activity patterns may also be a factor to take into consideration alongside seasonal climate differences, individual differences in behaviour, 'observer error' or the subtle influence of having another species in the outdoor-environment, when interpreting results or using these data as a comparison. Although only descriptive statistical comparisons were made throughout this study, sexual dimorphism should be another factor to consider when interpreting and comparing results between male and female study subjects in other institutions.

\subsection{Height Utilization}

As a species known to spend a vast majority of their time at height [3], zoos housing tree kangaroos are advised to build environments which both encourage and facilitate an arboreal lifestyle [17]. Despite the differences in age and sex class between the individuals studied, both study subjects utilized the highest height level within the indoor habitat most frequently (Figure 2a,b). During the study, the female did not spend any time at ground level. This is not uncommon for tree kangaroos as it has been observed that some species, including D. lumholtzi, are much more vulnerable to predation when on the ground [31]. Further work has stated that Lumholtz's tree kangaroos may come to the ground only as a flight response when startled, but then swiftly return to the forest canopy [32]. These works highlight the importance of understanding wild-type baseline behaviour in order to make accurate and species-appropriate interpretations of data collected in a zoo environment [33]. As such, for an arboreal animal such as a tree kangaroo, no utilization of the ground level of the indoor habitat should not be an area of great concern. However, the suggestion could be made to review the branching and structures within these under-utilised height levels to assess whether this area could be modified to facilitate easier access for the geriatric female, ensuring this individual can exercise a level of choice and control over their environment [34]. Anecdotally, towards the end of the study, observers noted the female subject utilizing a solid box within the exhibit, particularly as an area to rest. Thus, with collections housing older individuals, the implementation of wider more solid structures such as platforms may be of use to provide additional resting opportunities.

\subsection{Husbandry Routine}

Modern zoos aim to achieve more than simply exhibiting an animal to visitors [35]. Habitats and husbandry routines are continually enhanced to ensure animal welfare is the top priority. In order to create suitable environments and provide optimum care for individuals, a knowledge of the species' natural history is paramount [17]. As discussed, tree kangaroos are arboreal, forest dwelling species [19]. Thus, the habitat at Chester Zoo aims to facilitate an arboreal lifestyle by including a network of branching, plants and structures. Husbandry routines and the facility size allows individuals to be kept separately to replicate their solitary nature in the wild. Provision of a species appropriate diet of vegetables, leafy greens and browse meets the nutritional requirements for a folivore such as the tree kangaroo (Figure A1). The results of this behavioural study highlight that individuals at our facility do not engage in abnormal repetitive behaviour and have a mainly arboreal lifestyle. The provision of this information allows keepers to have an 
evidence-base from which to make management decisions and highlights areas for further improvement, such as the inclusion of additional structures for resting opportunities.

Overall, we hope the publication of this information will be useful to animal care staff and researchers, promoting individual-based monitoring and evidence-based management of this arboreal macropod. Additionally, the authors hope this work will contribute to the knowledge base surrounding zoo-housed tree kangaroos and will be of particular use to holders housing D. goodfellowi, a sub-species of tree kangaroo for which published information on zoo-housed individual behaviour is especially limited.

Supplementary Materials: The following are available online at https:/ /www.mdpi.com/article/10 .3390/jzbg3010009/s1, Video: S1.1-S1.7: Full descriptions of behaviour.

Author Contributions: Conceptualization, K.F.; methodology, K.F.; investigation, K.F.; resources, K.F..; data curation, K.F.; writing-original draft preparation, K.F. and A.H.; writing-review and editing, K.F. and A.H.; visualization, K.F. and A.H.; supervision, K.F. and A.H.; project administration, K.F. All authors have read and agreed to the published version of the manuscript.

Funding: This research received no external funding.

Institutional Review Board Statement: Ethical review for this study was waived due to the work conducted being purely observational with no manipulation to the study animal or their environment. Project was commissioned internally by Chester Zoo collections directorate staff.

Informed Consent Statement: Not applicable.

Data Availability Statement: Data available on request.

Acknowledgments: The authors would like to thank the Twilight, Curatorial and Science Teams at Chester Zoo for their support with this project. Particular thanks are extended to the following individuals: Rose Agnew, Megan Leary, Luke Heseltine, Leah Williams, Lisa Holmes, James Waterman, David White, James Andrewes, Kirsten Wicks, Peter Watson, Tim Rowlands, Nick Davis and Andrew McKenzie.

Conflicts of Interest: The authors declare no conflict of interest.

\section{Appendix A}
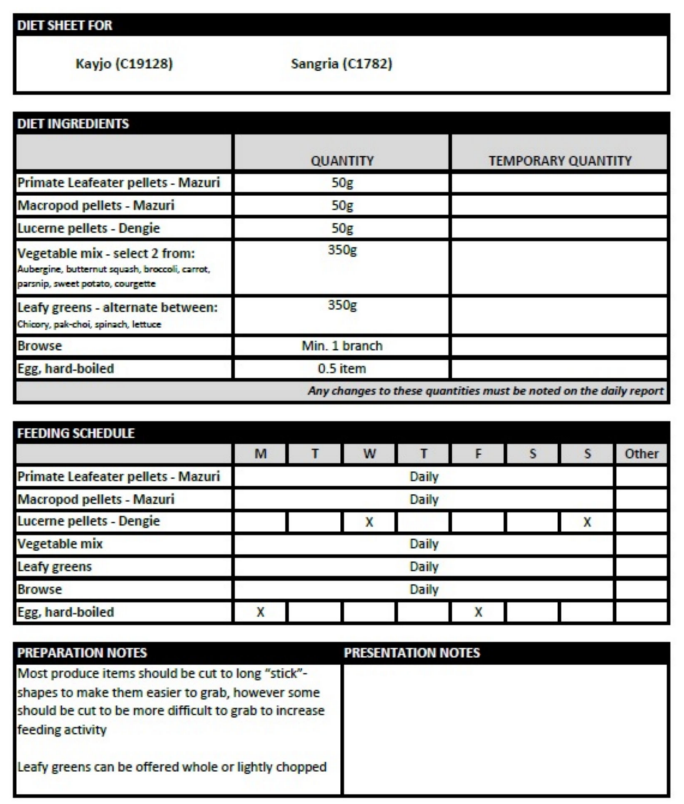

OTHER NOTES
Fruit (apple, pear or banana, max $50 \mathrm{~g}$ in total per day) can be used as training rewards

Figure A1. Diet sheet of Dendrolagus goodfellowii provided to study subjects throughout the observation period. Diet quantities displayed were those provided per individual. 


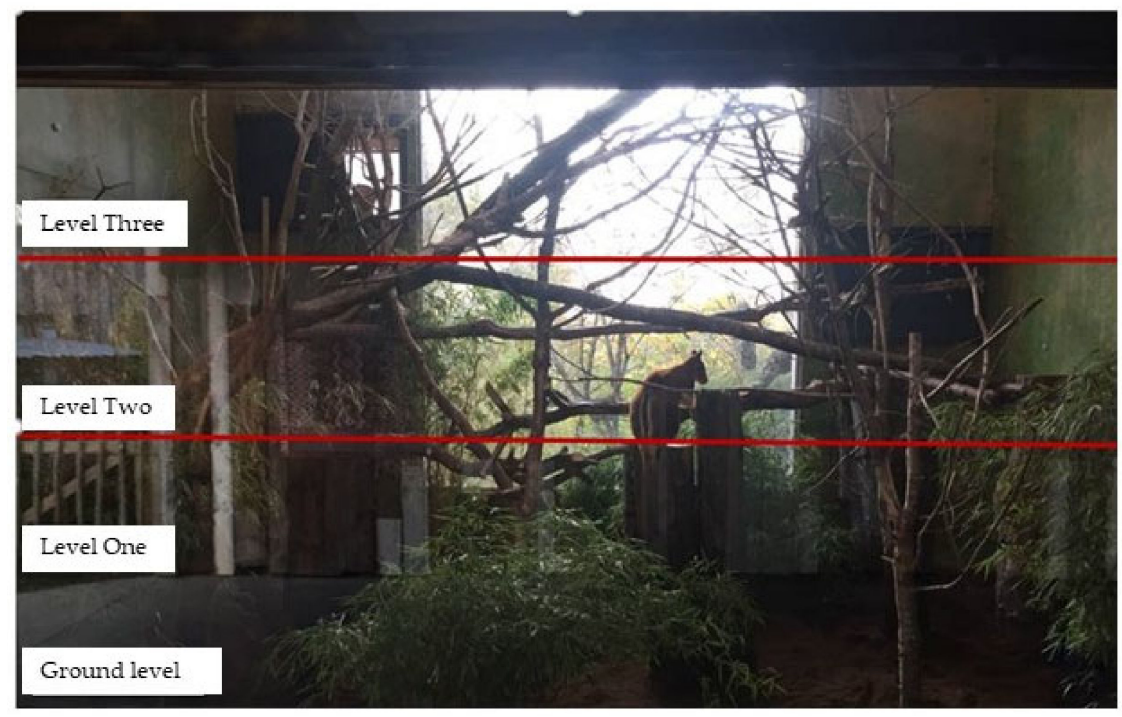

Figure A2. Image outlining pre-determined height levels used throughout data collection within the indoor habitat.

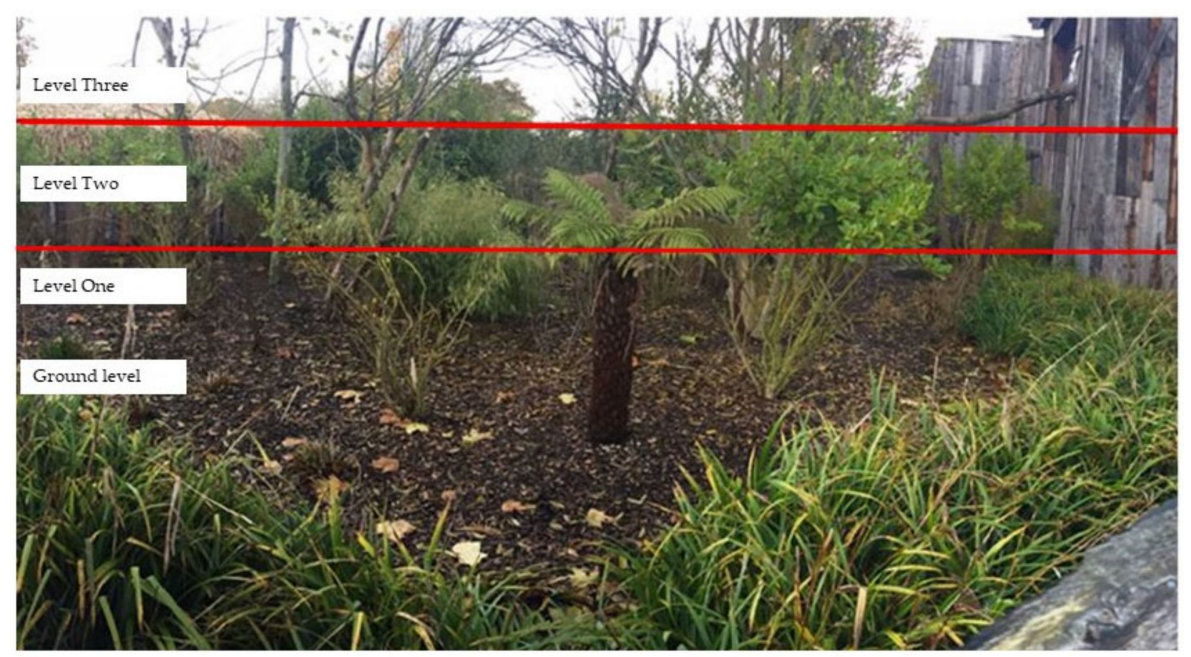

Figure A3. Image outlining pre-determined height levels used throughout data collection within the outdoor habitat.

\section{References}

1. Eldridge, M.D.B.; Potter, S.; Helgen, K.M.; Sinaga, M.H.; Aplin, K.P.; Flannery, T.F.; Johnson, R.N. Phylogenetic analysis of the tree kangaroos (Dendrolagus) reveals multiple divergent lineages within New Guinea. Mol. Phylogenet. Evol. 2018, 127, 589-599. [CrossRef] [PubMed]

2. Newell, G.R. Home range and habitat use by Lumholtz's tree-kangaroo (Dendrolagus lumholtzi) within a rainforest fragment in north Queensland. Wildl. Res. 1999, 26, 129-145. [CrossRef]

3. Valentine, P.; Dabek, L.; Schwartz, K.R. What is a tree kangaroo? Evolutionary history, adaptation to life in the trees, taxonomy, genetics, biogeography and conservation status. In Tree Kangaroos: Science and Conservation; Dabek, L., Valentine, P., Blessington, J., Schwartz, K., Eds.; Academic Press: Cambridge, MA, USA, 2020; pp. 4-5.

4. Warburton, N.M.; Yakovleff, M.; Malric, A. Anatomical adaptations of the hind limb musculature of tree-kangaroos for arboreal locomotion (Marsupialia: Macropodinae). Aust. J. Zool. 2012, 60, 246-258. [CrossRef]

5. Whitehead, M. Tree kangaroos. In The Management of Marsupials in Captivity; Partridge, J., Ed.; Association of British Wild Animal Keepers: London, UK, 1986.

6. Edwards, M.S.; Ward, A. Nutrition, food preparation and feeding. In Tree Kangaroo Species Survival Plan: Tree Kangaroo Nutrition Husbandry Manual; Steenberg, J., Blessington, J., Eds.; American Association of Zoos and Aquariums: Silver Spring, MD, USA, 2013; pp. 3-7. 
7. Heise-Pavlov, S.R. Evolutionary aspects of the use of predator odors in antipredator behaviours of Lumholt'z tree-kangaroos (Dendrolagus lumholtzi). In Chemical Signals in Vertebrates 13; Schulte, B., Goodwin, T., Ferkin, M., Eds.; Springer: Cham, Switzerland, 2016; pp. 261-280.

8. Heise-Pavlov, S.R.; Semper, C.; Burchill, S. Terrestrial activity patterns of the Lumholtz's Tree-Kangaroo (Dendrolagus lumholtzi) in a restored riparian habitat-Implications for its conservation. Ecol. Manag. Restor. 2021, 22, 183-190. [CrossRef]

9. Gillanders, A.; Wilson, C. Tree Kangaroo Tourism as a Conservation Catalyst in Australia. In Tree Kangaroos: Science and Conservation; Dabek, L., Valentine, P., Blessington, J., Schwartz, K., Eds.; Academic Press: Cambridge, MA, USA, 2020 ; pp. 109-125.

10. Byers, J.; Dabek, L.; Gabriel, P.; Stabach, J. Using telemetry and technology to Study the Ecology of Tree Kangaroos. In Tree Kangaroos: Science and Conservation; Dabek, L., Valentine, P., Blessington, J., Schwartz, K., Eds.; Academic Press: Cambridge, MA, USA, 2020; pp. 365-378.

11. Leary, T.; Seri, L.; Wright, D.; Hamilton, S.; Helgen, K.; Singadan, R.; Menzies, J.; Allison, A.; James, R.; Dickman, C.; et al. Dendrolagus Goodfellowi. Available online: https:/ /www.iucnredlist.org/species/6429/21957524 (accessed on 17 October 2021).

12. Dabek, L.; Valentine, P. The Future of Tree Kangaroo Conservation and Science. In Tree Kangaroos: Science and Conservation; Dabek, L., Valentine, P., Blessington, J., Schwartz, K., Eds.; Academic Press: Cambridge, MA, USA, 2020; pp. $433-437$.

13. Newell, G.R. Australia's tree kangaroos: Current issues in their conservation. Biol. Conserv. 1999, 87, 1-12. [CrossRef]

14. Hutchins, M.; Smith, R. Biology and status of wild tree kangaroos. In Proceedings of the AAZPA Northeastern Regional Conference Proceedings, Washington, DC, USA, 1 May 1990; pp. 500-509.

15. Blessington, J.; Steenberg, J.; Schwartz, K.R.; Schürer, U.; Smith, B.; Richardson MJaffar, R.; Ford, C. Tree kangaoo populations in managed facilities: Global species management plans (GSMPs). In Tree Kangaroos: Science and Conservation; Dabek, L., Valentine, P., Blessington, J., Schwartz, K., Eds.; Academic Press: Cambridge, MA, USA, 2020; p. 264.

16. McGreevy, T.J.; Dabek, L.; Husband, T.P. Microsatellite Marker Development and Mendelian Analysis in the Matschie's Tree Kangaroo (Dendrolagus matschiei). J. Hered. 2010, 101, 113-118. [CrossRef] [PubMed]

17. Blessington, J.; Steenberg, J. Tree Kangaroo (Dendrolagus spp.) Husbandry Manual, 3rd ed.; Tree Kangaroo Species Survival Plan; Kansas City Zoo: Kansas City, MO, USA, 2007.

18. Schwartz, K.R.; Byers, O.; Miller, P.; Blessington, J.; Smith, B. The Role of Zoos in Tree Kangaroo Conservation: Connecting Ex Situ and In Situ Conservation Action. In Tree Kangaroos: Science and Conservation; Dabek, L., Valentine, P., Blessington, J., Schwartz, K., Eds.; Academic Press: Cambridge, MA, USA, 2020; pp. 329-361.

19. Dabek, L. What is a tree kangaroo? Biology, Ecology and Behaviour. In Tree Kangaroos: Science and Conservation; Dabek, L., Valentine, P., Blessington, J., Schwartz, K., Eds.; Academic Press: Cambridge, MA, USA, 2020; pp. 17-29.

20. Martin, R. Tree kangaroo taxonomy. In Tree kangaroos of Australia and New Guinea; Martin, R., Ed.; CSIRO Publishing: Clayton, Australia, 2005; pp. 15-25.

21. Flannery, T.F.; Martin, R.; Szalay, A.L. Tree Kangaroos, A Curious Natural History; Reed Books: Port Melbourne, Australia, 1996.

22. Species360 Zoological Information Management System (ZIMS) (2021). Available online: www.species360.org (accessed on 10 October 2021).

23. Leary, T.; Seri, L.; Flannery, T.; Wright, D.; Hamilton, S.; Helgen, K.; Singadan, R.; Menzies, J.; Allison, A.; James, R. Dusky Pademelon, Thylogale brunii. Available online: https://www.iucnredlist.org/species/21870/21958826 (accessed on 25 January 2022).

24. Martin, P.R.; Bateson, P.P.G. Measuring Behaviour: An Introductory Guide, 3rd ed.; Cambridge University Press: Cambridge, $\mathrm{UK}, 2007$.

25. Time and Date Website. Available online: https://www.timeanddate.com/weather/uk/chester/historic (accessed on 1 January 2022).

26. Dabek, L. Mother-Young Relations and the Behavioural Development of the Young in Captive Matschie's Tree Kangaroos (Dendrolagus Matschiei). Master's Thesis, University of Washington, Seattle, WA, USA, 1991.

27. R Core Team. R: A Language and Environment for Statistical Computing; R Foundation for Statistical Computing: Vienna, Austria, 2013. Available online: http:/ / www.R-project.org (accessed on 15 October 2021).

28. Bishop, J.; Hosey, G.; Plowman, A. (Eds.) Handbook of Zoo Research, Guidelines for Conducting Research in Zoos; BIAZA: London, UK, 2013.

29. Travis, E.K.; Watson, P.; Dabek, L. Health assessment of free-ranging and captive Matschie's tree kangaroos (Dendrolagus matschiei) in Papua New Guinea. J. Zoo Wildl. Med. 2012, 43, 1-9. [CrossRef] [PubMed]

30. Davey, G. Visitors' Effect on the Welfare of Animals in the Zoo: A Review. J. Appl. Anim. Welf. Sci. 2007, 10, 169-183. [CrossRef] [PubMed]

31. Cianelli, M.; Schmidt, K. Rehabilitation of Lumholtz's Tree Kangaroo Joeys. In Tree Kangaroos: Science and Conservation; Dabek, L., Valentine, P., Blessington, J., Schwartz, K., Eds.; Academic Press: Cambridge, MA, USA, 2020; pp. 65-84.

32. Heise-Pavlov, S.; Procter-Gray, E. How an Understanding of Lumholtz's tree kangaroo behavioural ecology can assist conservation. In Tree Kangaroos: Science and Conservation; Dabek, L., Valentine, P., Blessington, J., Schwartz, K., Eds.; Academic Press: Cambridge, MA, USA, 2020; pp. 85-107.

33. Blessington, J.; Steenberg, J.; Richardson, M.; Norsworthy, D.; Legge, A.; Sharpe, D.; Highland, M.; Kozlowski, C.; Males, G. Reproductive Biology and Behaviour of Tree Kangaroos in Zoos. In Tree Kangaroos: Science and Conservation; Dabek, L., Valentine, P., Blessington, J., Schwartz, K., Eds.; Academic Press: Cambridge, MA, USA, 2020; pp. 309-327. 
34. Whitham, J.C.; Wielebnowski, N. New directions for zoo animal welfare science. Appl. Anim. Behav. Sci. 2013, 147, 247-260. [CrossRef]

35. Roe, K.; McConney, A.; Mansfield, C.F. The Role of Zoos in Modern Society-A Comparisons of Zoo' Reported Priorities and What Visitors Believe They Should Be. Anthrozoös 2014, 27, 529-541. [CrossRef] 